\title{
Brief Analysis of the Impact of "the Society of Spectacle" on the Ideological Safety of Chinese Universities
}

\author{
Li Chunyan \\ School of Marxism, Hubei University of Chinese Medicine, \\ Wuhan, Hubei 430074
}

\author{
Yang $\mathrm{Li}^{*}$ \\ School Office, Hubei University of Chinese Medicine, \\ Wuhan, Hubei 430074
}

\begin{abstract}
In order to explore the influence of "the Society of Spectacle" on the ideology of Chinese universities, this paper uses the methods of comparative analysis, literature research and expert interview to conduct an in-depth research through focusing on the research objectives. It finds and proves that, after the 21st century, Chinese society has presented some characteristics of "the society of spectacle", which has had a certain influence on the safety of leadership, management right, and discourse right in ideological work in universities. The innovation is to analyze the impact on the ecological safety of universities from the perspective of "the Society of Spectacle".
\end{abstract} safety

Keywords-The Society of Spectacle; Universities; Ideological

\section{INTRODUCTION}

In 1960s, French Ideologist Guy Ernest Dobord put forward the concept of "spectacle" and "the society of spectacle" in its work called The Society of the Spectacle. In the society of spectacle, the control of capital on society is converted to "image" control from commodity control, and its route is to use ubiquitous and fascinating "image" to increase people's personalized pursuit for commodities to a social mentality level, and then guide people to reflect the existing ideology in their behaviors, and finally loose subjective initiative in "image accumulation". After the reform and opening up, along with the overseas capital entering into China, under the impact of consumerism, Chinese social environment has also had certain degree of "spectacle" characteristics, and this has caused the new changes in the ideological work environment of universities

\section{THE TRANSFORMATION OF "SPECTACLE” TO “THE SOCIETY OF SPECTACLE” AND THE IDEOLOGICAL WORK ENVIRONMENT IN UNIVERSITIES}

From the perspective of external presentation, the concept of "spectacle" and "image", "external appearance", "presentation", "image", "picture" for the society of spectacle are closely related. However, Dobord personally paid more attention to the social relationship dissimilation behind spectacle and the ideological characteristics of spectacle, and it can be mainly reflected in two aspects: on one hand, Dobord held that "spectacle is not image accumulation, but the social

CLC Number: B036 Document Code: A Article No.: relationship of people taking image as the medium."'[1]Spectacle starts from the logic of "all stuff presented are good, and only good stuff can be presented" [2], and then through news, advertisement, entertainment and other modes, leads and even alienates the social relationship of the public, and tries hard to use aggressiveness, hard distinguishing, and conspicuous exhibition to guide the remodeling of social relationship, and further complete the dissimilation of the capital for social relationship. On the other hand, spectacle has ideological function, which is a form of expression for a kind of ideology serving for capital. "Through creating people's desire, and exerting ubiquitous objective temptations to us, spectacle inconceivably realizes the direct control of people in a deep unconsciousness level". [3] When the capitalist production relations is just established, capital mainly utilizes the desire of the exploited class for the basic survival demand to realize ruling, but along with the development of productivity and the improvement of social civilization degree, capital would like to use ubiquitous spectacle (image, and symbol) representing bourgeois ideology to realize the functions, and through publicizing "personalized consumption", and "demonstrative consumption", create false demand, and finally let people "voluntarily" approve the reasonability of capitalism ideology.

Since ideology is an indispensable part in the capital expansion process, generally, it will make joint contributions with the material production conditions to the creation of profits, and it is integrated with objective material interest, which is inseparable [4]. Thus, along with the promotion of reform and opening up in our country, "the society of spectacle" will certainly be penetrated to Chinese society along with the transfer of international capital. There are three reasons causing the ideological work environment in universities presenting certain "spectacle": firstly, scientific development and strong media can provide material foundation for the image (picture, and photo) expansion, and make the expansion of "image accumulation" possible in campus life; secondly, figurative language is easier to be accepted than verbal language, and it is almost a kind of "nothreshold" language, and even doesn't require too many knowledge reserves to understand the implication of certain image, and can provide convenience for the spectacle to spread its anesthetics through campus activities; thirdly, image culture consumption has ornamental and entertainment 
characteristics. College students are more inclined to pay attention to image-oriented "spectacle" information, and the essence is inclined to select sensory satisfaction over rational pursuit.

There are no doubts that, the ideological safety work achievements in universities have been quite remarkable over the years, but under the impact of "the society of spectacle", new problems and new challenges are hard to avoid. For instance, avoiding the enthusiastic participation of life and work, etc. due to the pursuit of vulgar material desire, the addiction to the pleasure brought by the "spectacle"; there is even the development trend from "commodity fetishism" towards "spectacle fetishism", i.e., everything can only acquire its own existence significance through converting to "spectacle" (image). In a few words, since "spectacle" can generate people's pleasant feelings, young and active college students can accept it more easily, and they are willing to accept consumption landscape (advertisement, entertainment film, movie, and games), and it is hoped that the so-called live quality can be improved as per "spectacle mode" (delicious food and fine view, fashionable dress and jewelries, home decoration,, villa and yacht), and they will even recklessly purchase certain commodities, knowing that the using value is nearly zero, and in the currently exposed news about "campus usury", one of the reflections is that partial college students are utilized by lawbreakers due to the purchase of luxuries (non-actual demand), so instead of saying that these college students pursuit gold and gaudy commodities, it would be fairer to say that they pursuit the "illusion" deep inside their hearts, and such illusion is exactly what the capital elaborately creates through "spectacle". Therefore, it is requested to explore the new problems and coping strategies faced by ideological safety in universities of our country under the view of "the society of spectacle" specific to the new characteristic of certain "spectacle" presented in the ideological work environment of universities.

\section{REMOVAL OF “THE SOCIETY OF SPECTACLE” FOR THE IDEOLOGICAL SAFETY IN UNIVERSITIES}

Through starting from Dobord's theory about the society of spectacle, it is not difficult to find out that the "spectacle" social environment can exert an obvious digestion function in the ideological safety of universities, and it can be especially reflected in the impact on the leadership, management right and speaking right of ideological safety in universities.

\section{A. Removal of ideological leadership safety in universities}

The impact of "the society of spectacle" on the ideological leadership in universities can be mainly reflected in the digestion of cultural recognition like main stream ideology, and there are two approaches: firstly, it is to realize the digestion of cultural recognition for main stream ideology through power penetration, and damage its appetency and emotional appeal, i.e., through inarguable and comprehensive spectacle display, realize the digestion of ideological leadership, and through showing the grand scenes, beautiful and charming beauties, and powerful expert lecture, etc., let people gradually accept the control and guidance of capital ideology. Dobord said that, "in the visual image of spectacle- ruling the economic order, there is no target, and development means everything, and the spectacle target is itself [8]. "Development means everything" shows the powerful spectacle, and a kind of undoubted and unstoppable trend of penetration extension. The only target thereof is to develop "spectacle" itself. Secondly, realize the digestion of cultural identity for the main stream ideology through recessive penetration. While conducting power penetration, spectacle can also be controlled through recessiveness, and let more people be governed by the "spectacle" , and more recognize "spectacle ideology". Such governance is mainly completed through consumption behaviors, and seemingly, people are freely purchasing commodities in the dazzling commodities, and never rethink about whether their own consumption desire is true demand or the false demand created by capital. They cannot realize the seemingly free purchasing choice is actually certain passive consumption, and the impulsion consumption under spectacle temptation. They have deviated from such rational criticism unconsciously, lost their own authenticity, and become the slave of spectacle [9].

\section{B. Removal ideological management right safety in universities}

The digestion of the "society of spectacle" for the ideological management right safety in universities is reflected in the separation of social relationship and the governance of social time. First of all, it is to realize the digestion of management right through the separation of social relationship. The management right of ideology requires reflecting its own in the integration of social relationships, but as for the "spectacle" social environment, "The more he expects, the less he lives; the more the main image he identifies as demand, the less he understands about his own survival and desire". [10]People's emotions, capacity and desires, etc. are separated by commodities, and college students cannot perceive their true demand inside. Secondly, "spectacle" can influence the ideology of college students through governing the time. "Spectacle" is good at using magnificent image to attract curious young people and those who enjoy attempting new things, and it will make them spend lots of time in the dazzling scene built by the spectacle, and use unconscious emotional culture to control them. "Landscape" exerts reversal desire drive on college students through time, and cause college students living away from the actual live demand of people under the temptation of film and television media as well as print media, separating Marxism belief, the socialism core value system and other main stream ideologies. 


\section{Removal of ideological speaking right safety in universities}

The digestion of "the society of spectacle" for the ideological speaking right safety in universities can be reflected in four aspects: firstly, through the permeation of thinking mode, seize the speaking right. In universities, the logic route is to realize the digestion of paradox between the falsity of social spectacle falsity and the authenticity of social existence, and let college students neglect the opposition for "yes" and "should" in the field of social culture, and then deprive the speaking right of main stream ideology. What they let the college students see is not a true object, but a symbol of object; what the college students feel is not the true feelings inside, but the feelings expected by the "spectacle". Secondly, through mandatory dialogue, deprive the speaking right of main stream ideology. Dobord said that, "when TV shows a beautiful picture, supplemented by some impudent and contemptible explanations likes lies, foolish people will believe that all of these are clear" [13] To some extent, in the social environment where medium is everywhere, media can build a cultural environment constructed by mandatory dialogue. If the environment of college campus is controlled by spectacle capital, it will certainly use its own powerful mandatory dialogue to weaken the speaking channel and speaking background of main stream ideology, and impact the ideological speaking right safety in universities. Just like what said by Michelle, "image not only cannot provide a transparent window to know about the world......, but also cover up a non-transparent, twisted and arbitral representation mechanism, and it is a mystification process of ideology.'"[14]

\section{SUGGESTIONS AND CONCLUSIONS}

"Preparedness ensures success, unpreparedness spells failure." For universities, the key to reinforce the dominant right of ideological work is whether the pre-alarm capacity of ideological safety can be improved, and since "spectacle" social environment has strong concealment for the "three rights" safety impact of consciousness in universities, only when the relevant safety pre-alarm capacity is improved, the possible risk damage can be predicted in advance, and the possible trend and future conditions of risks can be studied and judged in advance can the ideological safety in universities be truly ensured, and the dominant right of the party for the ideological field in universities be reinforced. The safety pre-alarm capacity for the ideological safety in universities refers to the administrative skill or administrative management capacity of universities to search, study and judge, and sound alarm as a social subsystem considering the threats that may endanger the guidance, cohesion and control force of main stream ideology through taking the leading role of main stream ideology as the orientation. According to the crisis response and treatment "perceiving-preventioncontainment-recovery-reflection" five-link theory[16]put forward by Barton (1993), the ideological safety warning capacity in universities shall include the alarm source precontrol for ideological safety crisis, the alarm sign evaluation, alarm condition research and judgment, alarm disaster disposal, operation guarantee and other aspects. In the spectacle social environment, the improvement of the aforementioned capacities can have a fundamental function and meaning for the ideological safety in universities. General Secretary Xi Jinping clearly pointed out in the report for the 19th National Congress of the Communist Party of China that, "the struggle in the ideological field of our country is still very complicated, and the national security is facing a new situation", "it is requested to constantly reinforce the leadership of ideological field" [15]. Only when the impact of "the society of spectacle" on the ideological safety in universities is deeply realized and measures are actively adopted to improve the pre-alarm capacity can the national security be reinforced.

\section{ACKNOWLEDGMENT}

Fund Project: The article is the phased research result of "the Influence of Information Alienation on University's Ideological Safety and Research on Construction of Early Warning Mechanism", a training program for young and middle-aged Marxist theoreticians from Hubei colleges and universities in 2016 (program number 16ZD066).

About the Author: Li Chunyan (1976-), female, the Associate Professor and Master Tutor for the School of Marxism, Hubei University of Chinese Medicine, and mainly studies Marxism Social Epistemology.

Corresponding Author: Yang Li (1978-), female, the Deputy Director and Lecturer for the School Office, Hubei University of Chinese Medicine and mainly studies college ideological and political education, and college students' psychological health education.

\section{REFERENCES}

[1] [France] Guy Dobord: The Society of Spectacle, translated by Wang Zhaofeng. Nanjing: Nanjing University Press, 2006, P6.

[2] [France] Guy Dobord: The Society of Spectacle, translated by Wang Zhaofeng. Nanjing: Nanjing University Press, 2006, P 4.

[3] Zhang Yibing: "Spectacle Ideology and Its Subversion-Tex Annotation for Dobord's The Society of Spectacle", Journal of Xuehai, 2005, P8.

[4] Augusto Ponzio: Karl Marx's Semiology [A]. Translated by Ren Wei. Refer to Contemporary Marxism Semiology Ideological Trend Selection, Editor-in-Chief $\mathrm{Hu}$ Yirong, and Chen Wenbin, Chengdu: Sichuan University Press, 2016, P36.

[5] [France] Guy Dobord: The Society of Spectacle, translated by Wang Zhaofeng. Nanjing: Nanjing University Press, 2006, P5.

[6] [France] Guy Dobord: The Society of Spectacle, translated by Wang Zhaofeng. Nanjing: Nanjing University Press, 2006, P114.

[7] [France] Guy Dobord: The Society of Spectacle, translated by Wang Zhaofeng. Nanjing: Nanjing University Press, 2006, P9.

[8] [France] Guy Dobord: The Society of Spectacle, translated by Wang Zhaofeng. Nanjing: Nanjing University Press, 2006, P135.

[9] [America] W•J•T Michelle: Iconology: Image, Text, and Ideology, translated by Chen Yongguo, Beijing: Peking University Press, 2012, P5

[10] Laurence Barton: Organizational Crisis Management, Beijing: Tsinghua University Press, 2002, P20.

[11] Xi Jinping: Realizing the Comprehensive Establishment of a Moderately Prosperous Society, and Obtaining the Great Victory of Chinese Characteristic Socialism in the New Era-the Report during the 19th National Party Congress, Beijing: People's Publishing House, 2017, P9. 